\title{
Queixas de uma cidade: entre a pauta e a ação política
}

\section{Silvana Monteiro*}

Levada para o meio acadêmico, uma inquietação oriunda de meu exercício profissional acabou se transformando em projeto de pesquisa. $O$ projeto, que pretendo desenvolver futuramente em um curso de mestrado, foi apresentado como meu trabalho final do curso de especialização em Assessoria de Comunicação da Universidade Federal de Goiás e aborda a relação entre população, imprensa e órgãos públicos e seus desdobramentos sociais, econômicos e políticos. Todos os dados apresentados são fruto de observação constante das citadas relações e devem servir de subsídio para a elaboração de um questionário que deverá revelar o perfil de cada um dos segmentos sociais envolvidos no processo de busca da cidadania.

Diariamente, pessoas de toda parte da região metropolitana de Goiânia procuram a redação do jornal $O$ Popular na tentativa de colocar um fim aos problemas de infra-estrutura que enfrentam em seus bairros. Eles acreditam que, por intermédio da equipe de reportagem, conseguirão se fazer ouvir pelos órgãos públicos municipais e estaduais, responsáveis pela solução desses problemas. Na maioria das vezes, estas pessoas procuram o jornal como "última alternativa", depois de inúmeras tentativas junto ao poder público. Parte dessa credibilidade advém do fato de os meios de comunicação e a mídia, de uma maneira geral, terem gozado, por determinado período, do status de quarto poder, aquele que media reivindicações e funciona como um contra-poder.

Para comunicadores como Ignácio Ramonet, a constituição de grandes conglomerados de comunicação vem colocar um fim a esse caráter de contestação, na medida em que se formam alianças entre mídia e poder. Embora a população já tenha se dado conta da iminente transformação, que pode ser facilmente verificada pelo exercício de uma "censura" norteada por interesses que extrapolam os sociais abrangendo outras esferas, como a econômica - , a crença de que os

\footnotetext{
* Jornalista, formada pela UFG, pós-graduada em Assessoria em Comunicação pela Facomb/UFG. Este texto, originalmente apresentado como trabalho de fim de curso, foi redigido na forma de projeto de pesquisa e com base na experiência profissional da jornalista, que trabalha na editoria de Cidades do jornal O Popular.
}

Comun. Inf., v. 6, n. 1, p.99-110, jan./jun. 2003 


\section{0}

meios de comunicação ainda falam mais alto que o direito à cidadania persiste. A esperança de que a consciência social se sobreponha ou, pelo menos, que não se interponha aos interesses econômicos das empresas de comunicação, ainda move a população nesse sentido. Talvez seja importante perceber qual o papel que cumprem as assessorias de comunicação dos órgãos públicos, que podem funcionar como seus apêndices, estabelecendo uma relação de cordialidade e até de cumplicidade com a mídia, mesmo que motivados por interesses meramente políticos.

Consciente ou não das relações que se desenrolam entre mídia e poder, a população recorre à primeira como mediadora de seus problemas. A prática não se restringe a nenhuma classe social específica e, aparentemente, não faz distinção de sexo, idade, grau de escolaridade ou de possíveis engajamentos políticos. O que parece existir é uma espécie de mecanismo comum, que leva as pessoas que moram na região metropolitana de Goiânia a solicitar cotidianamente, seja individualmente ou por meio de associações de moradores, a intervenção da redação do jornal $O$ Popular na mediação junto ao poder público, a resolução de problemas de infra-estrutura de seus respectivos bairros.

\section{Imprensa: de meio a canal de comunicação}

Em março de 2002 a direção do jornal O Popular decidiu, com base em pesquisas realizadas acerca de experiências bem sucedidas de jornais diários de outros países, reformular os projetos gráfico e editorial do jornal. O objetivo básico dessa reestruturação seria, em uma primeira instância, a de tornar o veículo mais acessível ao leitor, simplificando a linguagem e esquematizando-a por meios de quadros e gráficos para facilitar e direcionar a leitura. Na ocasião, foram criadas várias páginas de serviços, que circulariam em dias determinados da semana e seriam publicadas na contracapa do jornal.

Uma destas páginas, intitulada Bairros e Condomínios, passou a ser publicada sempre às quintas-feiras. A página traz uma reportagem enfocando um bairro ou condomínio específico da cidade, mostrando problemas referentes à infra-estrutura ou realizações passíveis de divulgação, onde toda a região metropolitana de Goiânia ${ }^{1}$ é objeto de reportagem. Na verdade, a criação da página veio atender a uma antiga e significativa demanda por parte dos moradores de Goiânia, que

Comun. Inf., v. 6, n. 1, p.99-110, jan./jun. 2003 
sempre tiveram por hábito acionar a redação como intermediadora na solução de problemas cujas medidas seriam de responsabilidade de órgãos municipais e/ou estaduais e autarquias.

Embora haja queixas de todas as naturezas, que contemplam desde problemas relativos àárea de saúde, como deficiência de atendimento nos Centros de Atendimento Integral à Saúde (Cais) e postos de saúde; e à de educação, como a falta de vagas nas escolas e creches, a página restringe-se a problemas de infra-estrutura nos bairros. Nesse caso, o foco é voltado para problemas como ausência de asfalto ou de redes de saneamento de esgoto, cuja solução seria de responsabilidade do Departamento de Estradas de Rodagens do Município (Dermu) e da Saneamento de Goiás S/A, respectivamente, ou para queixas a respeito da coleta de lixo e da roçagem de lotes, que deveriam ficar a cargo da Companhia Municipal de Urbanização (Comurg), só para citar alguns exemplos.

Como a demanda é muito grande e apenas a publicação de uma reportagem semanal não atenderia, nem de longe, a todas as reivindicações, ficou estabelecido que a página ainda comportaria uma coluna, intitulada Denúncias e queixas. A coluna, que divulga as reclamações dos moradores e publica, em seguida, uma resposta por parte do(s) órgão(s) competentes, responde a uma média semanal de quatro casos diferentes. Em semanas de grande mobilização é possível que o repórter receba até sete ligações, o que representa uma média de uma ligação diária ${ }^{2}$. As ligações partem de moradores indignados, de presidentes de associações de bairro, de cidadãos que desconhecem seus direitos e até de pessoas notadamente instruídas por terceiros ${ }^{3}$.

\section{Mercadoria para as massas}

A canalização da demanda de ligações e visitas por parte da população para um único repórter, que passaria a ter exclusividade sobre o assunto, foi mais uma maneira de otimizar o trabalho da equipe de redação e dar mais visibilidade ao assunto, concentrando-o em uma única página, com data definida para publicação. Não há como negar que, por trás do indiscutível papel social da criação da página, há interesses comerciais envolvidos, que remetem à incorporação das classes populares à cultura hegemônica, impulsionada pela indústria de narrativas, citada por Jesús Martin-Barbero (1997) em seu livro Dos meios às mediações: comunicação, cultura e hegemonia.

Comun. Inf., v. 6, n. 1, p.99-110, jan./jun. 2003 
Em seu livro, ele diz que

"em meados do século XIX, a demanda popular e o
desenvolvimento das tecnologias de impressão vão fazer das
narrativas o espaço de decolagem da produção massiva. O
movimento osmótico nasce na imprensa, uma imprensa que
em 1830 iniciou o caminho que leva do jornalismo político à
empresa comercial". (p. 169,170 )

A demanda popular se consolidou desde então, transformando os veículos de comunicação de instrumentos ideológicos em mercadorias. Por trabalhar com um produto altamente perecível, a imprensa não pode se dar ao luxo de contar com estoques "encalhados" e por isso investe em técnicas de marketing que não se resumem a estratégias de venda, mas de apresentação de conteúdo.

Sendo assim, a notícia passa a ter agregado a seu caráter político, caráter comercial. A medida atinge toda sua concepção, da pauta à publicação, passando pela execução em si e pela edição jornalística. Ou seja, uma reportagem não é feita apenas por convicções sociais, mas antes por se caracterizar como produto vendável tanto do ponto de vista do leitor, quanto do anunciante (que pode incluir pessoas ligadas ao poder público), e que quer ver seu nome e sua imagem ligados a conteúdos que traduzem sua ideologia e justifiquem seu investimento financeiro no jornal.

No entanto, essa estrutura de funcionamento não impede que o jornal seja também direcionado às massas, que representa uma fatia do mercado consumidor. Já no início do século XIX, ainda de acordo com Jesús Martin-Barbero, começa a se delinear uma imprensa voltada para as massas. É nesta época, segundo o autor, que surge o folhetim $^{4}$,

"primeiro tipo de texto escrito no formato popular de massa. Fenômeno cultural muito mais que literário, o folhetim conforma um espaço privilegiado para estudar a emergência não só de um meio de comunicação dirigido às massas, mas também de novo modo de comunicação entre as classes". (p. 171)

Comun. Inf., v. 6, n. 1, p.99-110, jan./jun. 2003 


\section{Relação simbiótica}

Estratégias de edição à parte, o que se apresenta como material importante para observação é a credibilidade que a população atribui ao jornal e a convicção de que o veículo tem um canal de livre acesso com o poder público que, por sua vez, teria estabelecido com a imprensa, de modo geral, uma relação de subserviência. De acordo com Jean-François Tétu (1997), o primeiro passo para o estabelecimento de uma "parceria" entre a mídia e o poder teria sido dado pelo Estado. O autor cita trechos de uma obra de P. Flichy (1991) onde ele mostra

“...de maneira bastante estimulante, como as primeiras formas de comunicação moderna (a rede de telégrafo, por exemplo) constituíram uma comunicação de Estado, i.e., ao mesmo tempo, algo que manifesta e torna efetivo o poder do Estado".(p. 431)

De instrumento do poder, a mídia teria passado, então, a coadjuvante, a partir da construção de uma relação que alimentasse interesses mútuos. O canal de comunicação entre as duas instituições passou a favorecer a ambas, a tal ponto que os veículos de comunicação também transformassem o Estado em uma ferramenta de trabalho. No campo da comunicação social Tétu (1997) cita como exemplo o surgimento das estações regionais de televisão na França, explicando que sua finalidade não era a de constituir uma mídia regional,

\footnotetext{
"mas eram criadas numa perspectiva de ordenação do território, da vontade de fazer as regiões saírem de seu encravamento, de tornar visível, por todos e para todos, o território de cada qual no seio de uma única televisão nacional" (Pág. 432).
}

Acredito que as massas também souberam se aproveitar da situação e começaram a reivindicar seus direitos por meio da mídia, que já havia estabelecido uma relação de livre acesso com o poder e mostrava interesse em discorrer sobre questões sociais. Tétu (1997) lembra que, recentemente, um comunicado do Conselho Econômico e Social $(O$ desenvolvimento dos fenômenos de comunicação e a participação na vida local, apresentado por M. Castagnet /1991) dava conta de que o local estava na moda, como

Comun. Inf., v. 6, n. 1, p.99-110, jan./jun. 2003 
“...resultado da conjunção de duas séries de fenômenos. Inicialmente, a emergência de toda uma série de atitudes novas em que, segundo o caso, podem-se ver os traços de uma sociedade 'pós 68', o triunfo de uma sociedade de consumo, ou o nascimento de uma era pós moderna. (...) O nascimento da ecologia e da atenção mais geral com o meio ambiente e com o quadro de vida, o crescimento de valores individuais, mas também a distância com relação aos problemas gerais da sociedade, que se traduz por uma indiferença generalizada (Baudrillard) (...) pretendem, a um dado momento, exprimir a esperança de uma profissão, de uma certa categoria da população ou de uma localidade mais ou menos vasta. Tudo isto conduz a uma forte recentralização sobre uma vida local.” (p. 433)

Nossa realidade local confirma todas estas tendências, a julgar pelo grande número de ligações (às vezes, mais de uma reclamando sobre o mesmo problema) e a repercussão das publicações, observada pelo número de ligações de retorno após a divulgação das reportagens e da coluna. A observação desse comportamento acabou por me despertar certa inquietação a respeito da relação entre população e imprensa, com finalidade políticas. Por que a necessidade desta mediação? E qual a real eficácia dela? Quais as falhas do sistema que levam a população a adotar este tipo de comportamento? E quem são estas pessoas, que procuram o jornal como mediador?

Para entender como se consolidou este comportamento seria preciso partir da explicitação dos motivos que levam a população a buscar meios alternativos para a solução de seus problemas, como que numa espécie de protesto contra a ineficácia dos meios "oficiais", supostamente criados pelo Estado com a finalidade de atender ao povo.

\footnotetext{
"Desde o início da Reforma, e de maneira explícita nos Discorsi de Maquiavel, vemos organizar-se em torno da figura do povo a busca de um novo sistema de legitimação do poder político",diz Jesús Martin-Barbero. (1997, p. 23)
}

Em seu livro seu livro Dos meios às mediações:comunicação, cultura e hegemonia, Barbero (1997) cita Maquiavel como defensor de que 'boas leis surgem dos tumultos', em contraposição a Tocqueville, que vislumbra uma espécie de pacto entre a sociedade e as massas, na medida em que estas últimas transmutam-se de "turbas que ameaçam com sua barbárie a sociedade (...) em multidão urbana” (p. 44), fruto do processo de igualitarismo social. Verificar até que ponto esse

Comun. Inf., v. 6, n. 1, p.99-110, jan./jun. 2003 
igualitarismo social se consolidou também pode ser esclarecedor para o entendimento mais amplo deste quadro. A princípio, existe uma tendência em pensar que apenas moradores de bairros periféricos ou de menor poder aquisitivo procurem o jornal como mediador de soluções junto ao poder público, já que, hipoteticamente, não teriam acesso aos mesmos mecanismos de cidadãos de classes abastadas (assessoria jurídica, relações pessoais com membros do poder, etc.).

\section{No topo da pirâmide}

É possível esboçar um perfil desses moradores, a partir de um levantamento das reportagens, queixas e denúncias publicadas, respectivamente, na página Bairros e Condomínios e na coluna Denúncias e queixas, durante os seis primeiros meses de circulação, entre 11 de abril e 10 de outubro de 2002 . Nesse período, foram publicadas 27 reportagens, das quais treze traziam a divulgação de iniciativas bemsucedidas em condomínios, como a adoção de medidas para reduzir a taxa de condomínio ou o investimento dos moradores em preservação ambiental e quatorze denunciavam problemas de infra-estrutura dos bairros, como falta de asfalto, moradias em áreas de risco e poluição sonora.

O equilíbrio entre soluções e problemas, no entanto, ficou restrito às reportagens, já que a coluna Denúncias e queixas publicou uma média de 80 reclamações, a maioria proveniente do município de Goiânia, com mais de $70 \%$ da demanda, seguida pelo município de Aparecida de Goiânia, com 14,3\% das reclamações. Os municípios de Senador Canedo e Trindade vêm empatados em terceiro lugar, com $6 \%$ do total das queixas e as outras cidades que compõem a região metropolitana de Goiânia não figuram entre os reclamantes (Fig.1). Contradizendo às expectativas iniciais, são os moradores dos bairros ditos nobres os que mais recorrem ao jornal.

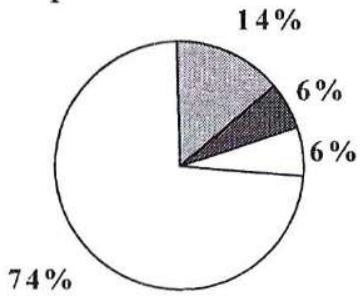

$\square$ A parecida de Goiânia

Trindade

$\square$ Senador Canedo

$\square$ Go iân ia

Figura 1 - Municípios de onde partem as denúncias ao jornal O Popular 2002.

Comun. Inf., v. 6, n. 1, p.99-110, jan./jun. 2003 


\section{6}

Cerca de $40 \%$ das queixas são provenientes desses bairros, sendo que as denúncias que partem do Setor Sul e do Setor Oeste são as mais recorrentes. Queixas oriundas do Setor Bueno, Setor Marista, Jardim América, Bairro Alto da Glória, Centro e Setor Coimbra também aparecem em destaque e o Bairro Floresta, situado na região Noroeste da capital e conhecido por sua infra-estrutura precária, figura entre aqueles de onde parte o maior número de demandas devido a uma peculiaridade: um mesmo morador, que não se identificou como presidente de associação de bairro, acionou a redação três vezes, para fazer queixas a respeito de diferentes problemas.

A concentração de demanda não exclui os bairros periféricos ou populares, que se revezam a cada publicação reclamando por seus direitos. Seria cansativo listar todos os bairros que aparecem nas queixas publicadas nesse período de seis meses, mas é possível afirmar que a cidade como um todo se mobiliza na busca de mediação por parte do jornal e as queixas, apesar de o serem igualmente múltiplas, podem ser classificadas por número de ocorrências. A principal queixa diz respeito à falta de asfalto, seguida por reclamações acerca do trânsito, que podem incluir estacionamento indevido, falta de sinalização e deficiência na fiscalização, entre outras. As queixas sobre saneamento aparecem em terceiro lugar e, logo depois, vêm as solicitações para a revitalização de praças públicas.

Em menor número, são registradas queixas contra falhas no serviço de fiscalização urbana, como a presença de ambulantes em calçadas, poluição visual e sonora e vandalismo; falta de iluminação pública, além de questões referentes ao lixo, como deficiência na coleta e poluição de áreas públicas. Questões referentes à segurança, transporte coletivo, pedidos para retirada de árvores, moradia e prevenção da dengue aparecem quase que de forma isolada, entre outras denúncias e solicitações. O percentual da soma desses problemas que, por força das circunstâncias, definiremos como minoritários, equivale ao percentual de solicitações de asfalto, que é igual a 22\% do total de reclamações.

$\mathrm{Na}$ figura 2, mostrada a seguir, estão relacionados os principais tipos de reclamações que são feitas ao jornal pelos moradores.

Comun. Inf., v. 6, n. 1, p.99-110, jan./jun. 2003 


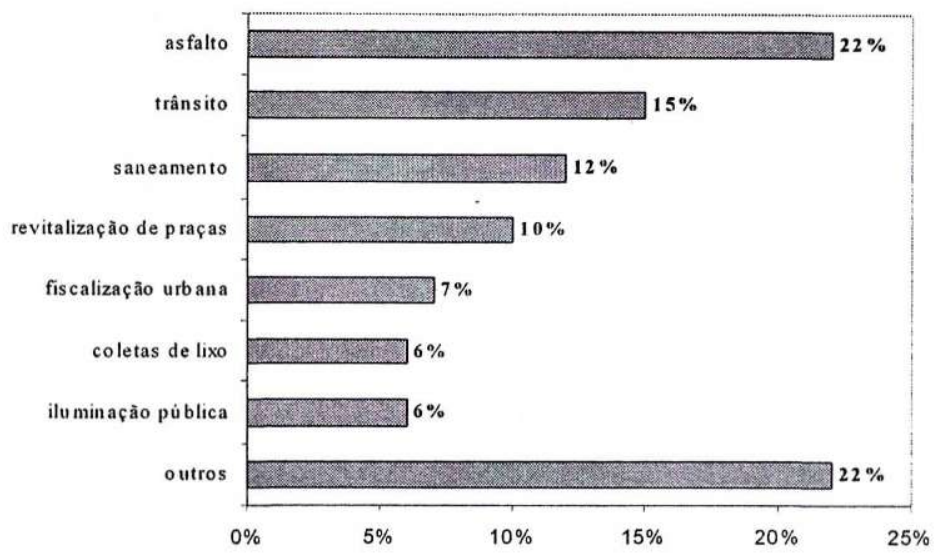

Figura 2 - Problemas apontados pelos leitores do jornal O Popular. Região metropolitana de Goiânia. 2002.

Se os problemas são comuns a pessoas de diferentes bairros, não se pode dizer o mesmo da origem das solicitações por parte dos moradores que, em mais de $80 \%$ dos casos, é feita de forma individual. Em números quase equivalentes, são registradas as denúncias feitas coletivamente, por grupos de moradores, e aquelas provenientes de representantes de bairros e/ou associações de moradores, nesta ordem (Fig.3). Os homens também são maioria entre os reclamantes, perfazendo um percentual de $65 \%$ das queixas (Fig.4). Neste breve estudo preliminar ainda foi possível observar que eles são também maioria absoluta entre os presidentes de associações de moradores de bairros e as mulheres, geralmente, são moradoras dos bairros ditos nobres da capital.

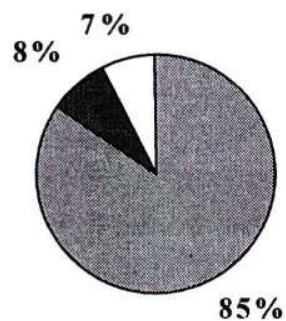

$\square$ in dividualmente

coletivamente

$\square$ por meio de asso ciações de moradores

Figura 3 - Como são feitas as queixas ao jornal O Popular Região Metropolitana de Goiânia 2002.

Comun. Inf., v. 6, n. 1, p.99-110, jan./jun. 2003 


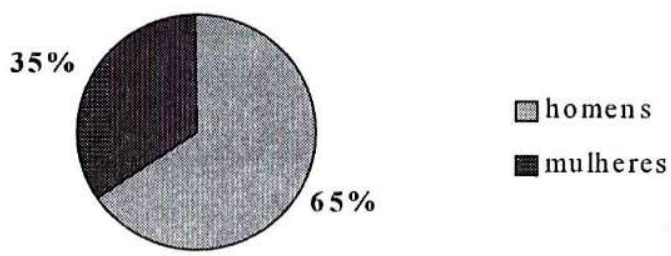

Figura 4. Distribuição da freqüência, por sexo, dos autores das denúncias ao jornal O Popular Região metropolitana de Goiânia. 2002

Sem a realização de um estudo com o rigor do método científico, no entanto, seria impossível "conhecer" essas pessoas e identificar os reais motivos que as levam a acionar a imprensa. Apenas a observação diária ou um levantamento superficial, sem respaldo metodológico, não nos permite traçar um perfil destes representantes da população, já que as abordagens partem de indivíduos de ambos os sexos, de idades as mais diversas possíveis, e de classes sociais bem distintas, como pôde ser observado pela procedência das queixas, que partem de bairros nobres e populares. O nível cultural destas pessoas também não fica evidente por meio dos contatos telefônicos, pessoais ou eletrônicos, bem como o grau de escolaridade das mesmas, nível de envolvimento na comunidade e acesso aos meios de comunicação.

"De maneira geral, nas últimas duas décadas as formas de vida urbana e o tamanho das aglomerações modificaram a percepção da identidade local dos habitantes e empurraram a imprensa a procurar novas formas de apreensão da informação local. (...) A determinação da 'localidade', pelo menos na imprensa escrita, é menos geográfica e econômica que institucional".(Jean-François Tétu, 1997, p. 439).

Também a população, mas não apenas a mídia, toma consciência dessa identidade local e passa a se articular para moldá-la de forma a atender interesses comunitários e pessoais. A massa reconhece nos meios de comunicação uma ponte, um atalho, que a levará a um contato, ainda que de forma indireta, com o poder público, seu alvo final.

Um caminho tortuoso, se levarmos em consideração que envolve mediações paralelas e jogos de interesses alheios aos da própria população. A escolha do modelo de busca de soluções de problemas, no entanto, parece ter se mostrado um caminho, se não satisfatório,

Comun. Inf., v. 6, n. 1, p.99-110, jan./jun. 2003 
pelo menos, viável. Resta saber se ele foi escolhido por opção, conveniência ou exclusão e verificar até que ponto os resultados obtidos apontam para a continuidade do sistema. Vale citar que "o espaço público(...) não é um espaço real, mas um espaço simbólico, feito de saberes e de representações". (Jean-François Tétu, 1997, p. 431) Na medida em que a simbologia dos espaços varia de acordo com o grau de conscientização social e de autoconhecimento da população, as mudanças nos mecanismos de busca de cidadania se darão conforme o amadurecimento da massa em relação à própria realidade.

\section{Abstract:}

The author considers the role of the newspaper O Popular, in Goiânia, as an intermediate between the public and the local governement, based on the complains that the public send to the newspaper.

Key words: Newspaper, complanis, public sphere.

\section{Notas}

1 A região metropolitana de Goiânia foi instituída pela lei complementar $n^{\circ} 27$, de 30 de dezembro de 1999, fazendo com que, juntos, os municípios de Abadia de Goiás, Aparecida de Goiânia, Aragoiânia, Goianápolis, Goianira, Goiânia, Hidrolândia, Nerópolis, Santo Antônio de Goiás, Senador Canedo e Trindade constituíssem a "Grande Goiânia".

2 A grande maioria das reivindicações é feita por telefone, embora alguns (poucos) leitores se utilizem da internet como meio de comunicação (a página dispõe de um endereço eletrônico) e uma insignificante minoria acione a redação do jornal por meio de cartas enviadas pelo correio ou por visitas pessoais.

3 Já foram observados alguns casos em que os moradores afirmam ter sido orientados por políticos, quase sempre vereadores oriundos dos próprios bairros onde ocorre o problema, a procurar o jornal para fazer a mediação entre eles e o poder público. Este tipo de cidadão, quase sempre mostra-se mais bem informado sobre os problemas para os quais deseja solução e, não raro, dispõe de documentos que legitimam sua reivindicação. A formação de grupos, ou comitivas, também é regra nesse tipo de abordagem.

4 Antes de significar romance popular publicado em episódios ao longo de um certo período, folhetim designava uma parte do jornal: o "rodapé" da primeira página, onde iam parar as "variedades", as críticas literárias, as resenhas teatrais, junto com os anúncios e receitas culinárias, e não raro com notícias que metiam a política em disfarce de literatura. p.171

\section{Referências}

ANDRÉ, Marli Eliza Dalmazo Afonso de. Etnografia da prática escolar. Campinas/SP. Papirus, 1995.

BASTOS, Lília da Rocha; PAIXÃO, Lyra; FERNANDES, Lucia Monteiro;

Comun. Inf., v. 6, n. 1, p.99-110, jan./jun. 2003 


\section{0}

MARTIN-BARBERO, Jesús. Dos meios às mediações: comunicação, culturae hegemonia. Rio de Janeiro/RJ. Editora UFRJ, 1997.

RAMONET, Ignácio. A tirania da comunicação. Petrópolis/RJ. Editora Vozes, 1999.

SEVERINO, Antônio Joaquim. Metodologia do trabalho cientifico. São Paulo/ SP. Cortez Editora, 2002.

TÉTU, Jean-François. A informação local; espaço público local e suas mediações. In: MOUILLAUD, Maurice; PORTO, Sérgio Dayrell. Ojornal: da forma ao sentido. Brasília/DF. Paralelo 15, 1997.

Comun. Inf., v. 6, n. 1, p.99-110, jan./jun. 2003 